IZADP No. 1711

Contests, NGOs and Decentralizing Aid

Gil S. Epstein

Ira N. Gang

August 2005 


\title{
Contests, NGOs and Decentralizing Aid
}

\author{
Gil S. Epstein \\ Bar-llan University \\ and IZA Bonn \\ Ira N. Gang \\ Rutgers University \\ and IZA Bonn
}

\section{Discussion Paper No. 1711 \\ August 2005}

\author{
IZA \\ P.O. Box 7240 \\ 53072 Bonn \\ Germany \\ Phone: +49-228-3894-0 \\ Fax: +49-228-3894-180 \\ Email: iza@iza.org
}

Any opinions expressed here are those of the author(s) and not those of the institute. Research disseminated by IZA may include views on policy, but the institute itself takes no institutional policy positions.

The Institute for the Study of Labor (IZA) in Bonn is a local and virtual international research center and a place of communication between science, politics and business. IZA is an independent nonprofit company supported by Deutsche Post World Net. The center is associated with the University of Bonn and offers a stimulating research environment through its research networks, research support, and visitors and doctoral programs. IZA engages in (i) original and internationally competitive research in all fields of labor economics, (ii) development of policy concepts, and (iii) dissemination of research results and concepts to the interested public.

IZA Discussion Papers often represent preliminary work and are circulated to encourage discussion. Citation of such a paper should account for its provisional character. A revised version may be available directly from the author. 
IZA Discussion Paper No. 1711

August 2005

\section{ABSTRACT}

\section{Contests, NGOs and Decentralizing Aid*}

International donors usually have particular goals they want to achieve with their foreign aid, for example, poverty alleviation. In the international aid story lobbying by potential recipient groups attempting to capture the donor's support play a potentially important role for nongovernmental organizations. We model this situation as a hierarchical contest and compare the implications of a centralized allocation process with a decentralized allocation process with nongovernmental organizations as intermediaries.

JEL Classification: F35, D72

Keywords: contests, NGOs, aid

Corresponding author:

Ira N. Gang

Economics Department NJH

Rutgers University

75 Hamilton St.

New Brunswick NJ 08901-1248

USA

Email: gang@economics.rutgers.edu

\footnotetext{
* An earlier version of this paper was present at the HWWA Conference on Public Choice and Development, The Political Economy of Aid, December 9 - 11, 2004, Hamburg, Germany. We thank the participants and two anonymous referees for their comments. Some of this work was complete while Epstein and Gang were visiting IZA, Bonn, which we thank for its courtesy.
} 


\section{Introduction}

During the 1990s the numbers and roles of international nongovernmental organizations (NGOs) taking part in the foreign aid process grew. For all the Development Assistance Committee (DAC) countries, official development assistance (ODA) to NGOs increased from US\$928 millions in 1991-1992 to US\$1246 millions in 2002, and increase of $34 \%$. This represents an increase from 1.59 to 2.14\% of all DAC ODA from 1991-1992 to 2002. For the United Kingdom, a country where this shift is quite stark, the funding of ODA to NGOs went from US\$21 to US\$226 millions, an increase of $976.2 \%$, and from $0.65 \%$ of all UK ODA in $1990-1991$ to $4.6 \%$ in 2002 . The number of international NGOs grew by $19.3 \%$ during the decade. $^{1}$

One explanation for this expansion is that, due to a multitude of domestic and international political and economic forces, it became prudent for many national development agencies around the world to subcontract - or outsource - their aid activity. The standard multilateral institutions had taken up some of this in the 1970s, but had their own reputation issues by the 1990s. NGOs, on the other hand, usually have well-defined goals allowing donor government policy to be achieved by funding the NGOs which have a similar mindset. Also NGOs are independent of governments, and they have a dedicated workforce whose goals are generally to serve local needs. This allows them, it is argued, to function with lower costs then government aid agencies, also providing a flexible labor force with fewer administrators for governments looking to cut back on the size of their bureaucracy. ${ }^{2}$

We explore another aspect of the introduction of NGOs into the aid story. We start from the presumption that lobbying affects the decision making of the donor (See Epstein and Nitzan 2002b). This opens the door to influencing the donor via aid-seeking activities. We ask the question: Is the donor agency in its quest to achieve its goals better off allocating its aid directly to the targeted subgroups of the recipient population or their representatives, or is 
it better off donating its aid through NGOs. In our model, there are competing NGOs and competing subgroups. We are interested in the competition for aid funds and the structure of their allocation.

The donor may have a particular goal in its aid program, or it may be trying to satisfy multiple goals. To simplify the discussion in this paper we assume the donor government's aim is poverty reduction, a major goal of aid policy over the last thirty years. The donor is particularly interested in allocating funds to the poorest segments of the population. At the same time, however, the donor is concerned with wasteful disposition of its aid in bureaucratic activities. In the background the donors own domestic constituents appreciate an efficiently run aid dispersion process, and well as poverty reduction.

To answer our question we set up a model of hierarchical lobbying for aid by NGOs and subgroups of the population, and compare the implications of a centralized allocation process with a decentralized allocation process. In an attempt to increase efficiency the donor may choose to allocate aid directly to constituent groups or it may choose to decentralize decision-making by allocating the aid to, for example, different NGOs. The NGOs, in turn, will allocate aid to the different groups within its clientele.

In essence, we are comparing the outcome of a one-stage game (the donor makes its grants directly to competing subgroups) to the outcome of a two-stage game (the donor makes its grants to NGOs which make grants to competing groups) (see Baik and Lee, 2000). We take into account the preferences the donor has regarding the needs of the different groups. We also provide some insight into the question of how decentralization increases or decreases total aid-seeking activity, and how the preferences the donor and the NGOs tolerance of poverty affects aid-seeking activity and the probability of receiving aid. With this in mind, in the next section we establish and analyze a model of hierarchical aid-seeking 
in which potential recipients compete for aid funds. Later in the paper we show the potential existence of a poverty trap as a result of channeling aid through NGOs.

In the rent-seeking literature from which we draw, it has been established that asymmetry between the contestants reduces wasteful lobbying efforts. The asymmetry can be in terms of the lobbying capabilities, endowments, and attitudes toward risk or rent valuations of the contestants, as in, for example, Allard (1988), Gradstein (1994), Nitzan (1994), and Nti (1999). In a similar way, in our model asymmetry affects lobbying efforts and thus the probability of receiving a share of the aid.

\section{The Model and Analysis}

In our model there are three layers in the hierarchy. The top layer is the donor government or aid agency, such as USAID, or one of the international development banks, such as the World Bank. The intermediate level contains the NGOs who receive funds from the donor and are responsible for allocating the funds they receive to various subgroups of the potential recipient population, possibly groups in different countries, possibly subgroups within the same country. Generally, some agency or political entity represents these subgroups, though it is possible for a subgroup to only have one member. The subgroups may request funds from the NGOs or from the donor. Of course, there are many other hierarchical relations we could describe. $^{3}$

In our setting the donor wishes to attack poverty. On the other hand, the NGOs are assumed to maximize the expected funds obtained while, at the same time, they value the social welfare (the economic status) of their constituent groups. We assume, as in Epstein and Nitzan (2002b), that the objective of the donor when being lobbied is a weighted function of the lobbying effort and social welfare. The NGOs have the same objective when lobbied by constituent groups. However, when NGOs lobby donors it is assumed that they maximize 
their expected payoff as described above. These two possibilities do not contradict each other.

The economic status of subgroup $i$ (denoted by $w_{i}$ ) plays an important role in the model. It represents both the economic needs of the subgroup - the lower is $w_{i}$ the poorer is the subgroup and the more funds it needs - and the cost of lobbying for aid. Lobbying is time consuming, decreasing the time spent on productive activities; it is therefore costly in terms of lost income. The lower the economic status of the subgroup the lower the opportunity cost of lobbying. The cost of lobbying per unit of lobbying is $w_{i}$. This is certainly a reasonable assumption when analyzing some important countries such as Bangladesh or India, where local NGOs often come from the grass root. However, in many other parts of the world, NGO activists are typically from middle class or foreigners who get involved in social action either for the sake of altruism, or simply for profit. The opportunity cost of their lobbying time is not reflected in the average income of the groups for whom they care. However, the NGO sees the activists' opportunity cost in terms of the NGO's resources and, all in all, we can think of opportunity cost as being a positive function NGO wealth. Thus we use the NGO's wealth as a proxy for opportunity cost.

For simplicity, we assume there are two NGOs, NGO-A and NGO-B. The NGOs interests are aligned with the poor, whether the NGOs arise from the poor themselves, are run by the local middle and upper classes, or are international in origin. Their goal is also poverty alleviation. However, they are also pragmatists working in the world of grant-getting and dealing with governments. As such, they are willing to make trade-offs to ensure their piece of the pie and their survival. All NGOs are not the same - they may differ in size and in the groups they represent. We first discuss the information structure and then consider two specific cases: (a) In the first stage both NGOs lobby the donor for funds. In the second 
stage each subgroup lobbies its NGO to obtain part of the funds the NGO received. (b) The subgroups lobby the donor directly.

\section{Government actions}

We assume that the aid the donor has to distribute is fixed and exogenous. As in Epstein and Nitzan (2002a, 2002b) and Epstein and Gang (2003), donor politicians and bureaucrats are recipients of the lobbying efforts of NGOs and subgroups. Lobbying efforts may be, for example, time/dollars spent in preparing proposals for submission to the donors or hiring lobbyists to help make the subgroups case; in corrupt regimes lobbying efforts may take the form of direct payments to members of the donor hierarchy, political and business connections, or other such relationships. Below we specify the role of the donor and its objectives more formally.

Consider the preferences the donor has towards the objective needs of the NGOs/subgroups. ${ }^{4}$ The donor's preferences help determine the contest-success function. The donor is assumed to choose which NGO/subgroup to help. Assume that donors consist of people who are affected by lobbying effort for political and other reasons (see for example, Epstein and Nitzan, 2002a, 2002b, 2004; Grossman and Helpman, 1994). The probability that an NGO or a subgroup wins part of the available aid is therefore a function of the lobbying effort $(L)$, the needs of the NGO/subgroup $(w)$ and the preferences of the donor with

regard to poverty (or the donor's tolerance of poverty) - the need of the groups $(\alpha)$. This is captured in our contest success function, $\operatorname{Pr}_{i}$, described below.

\section{Case A: Donor, NGOs and Subgroups}

A.1. Competitive NGOs. The donor allocates $R$ aid funds to the different subgroups via the two NGOs, A and B; $L_{i}$ is the lobbying effort of NGO $i$ attempting to extract aid from 
the donor while $\left(1-L_{i}\right)$ is the fraction of the NGO's resources not used up in lobbying. $\operatorname{Pr}_{i}$ is the proportion/probability NGO $i$ receives out of the total aid the donor has to allocate. Therefore, the expected amount of aid that this NGO will obtain is $\operatorname{Pr}_{i} R$. As stated above the needs of each NGO play an important role in the analyses. Let $w_{j}$ represent the "lack of poverty indicator" of subgroup $j$ and $k_{i}$ represents the "weight” of that subgroup in the NGOs objective (the weight may be a function of different variables) thus the average economic status would be given by: $v_{i}=\sum_{j \in i} k_{j} w_{j} \quad$ for $i=A, B$,

It is assumed that the NGOs wish to maximize the expected funds obtained and at the same time the NGOs value the social welfare (the economic status) of its constituent groups. The NGOs are risk neutral. The objective of NGO $i$ is to maximize its expected payoff, given by:

$$
E\left(U_{i}\right)=\left(1-L_{i}\right) v_{i}+\operatorname{Pr}_{i} R \quad \forall i=A, B
$$

The probability/proportion an NGO receives funds, $\operatorname{Pr}_{i}$, is: (1) a positive function of the lobbying effort of NGO $i, L_{i}$; (2) negatively affected by the lobbying effort of NGO $j, L_{j}$. (3) negatively related to the economic status of NGO $i, v_{i}$; and (4) positively related to the economic status of NGO $j, v_{j}$. As $v_{i}$ increases NGO $i$ is better off - its client groups have less involvement with poverty - and thus will need less funds from the donor. (5) $\operatorname{Pr}_{i}$ is also a function of the preferences the donor has regarding the economic status of the NGOs $(\alpha)$. As $\alpha$ increases the probability/proportion of funds going to the NGO with the low $v$, which is to the needy, increases. For $v_{i}<v_{j}$ it holds that $\frac{\partial \operatorname{Pr}_{i}(.)}{\partial \alpha}>0$ and $\frac{\partial \operatorname{Pr}_{j}(.)}{\partial \alpha}<0$. (6) Moreover, we assume that the size of the NGO is also a factor determining the probability of receiving 
aid. The idea behind this assumption is that larger NGOs have more weight in effecting the decision making of the donor (the larger the size of the NGO the more noise it can make and the more influence it has on election day). We also think about this as the relative lobbying ability of the different NGOs. In order to simplify, we assume that this ability is a direct function of the size of the NGO. We normalize the size of NGO-B to unity. Therefore, the effect of the size of NGO-A is denoted by $d$, which is a positive function of the size of NGOA. Without loss of generality, we assume that $N G O-A$ is larger than $N G O-B$ or alternatively $A$ is better at lobbying than $B: d>1$.

The contest success function we employ is a variant of the non-discrimination rule of the Tullock (1980) function. This function satisfies all the properties presented above. NGOi's probability/proportion of receiving aid is

$$
\operatorname{Pr}_{A}=\frac{d L_{A}\left(v_{A}\right)^{-\alpha}}{d L_{A}\left(v_{A}\right)^{-\alpha}+L_{B}\left(v_{B}\right)^{-\alpha}} \text { and } \operatorname{Pr}_{B}=1-\operatorname{Pr}_{A}
$$

where $L_{i}\left(v_{i}\right)^{-\alpha}=L_{i} v_{i}\left(v_{i}\right)^{-\alpha-1}$. $L_{i} v_{i}$ is the value of lobbying and $v_{i}^{-1}$ is the weight or the level of need of the NGO. Thus there are decreasing marginal effects to lobbying. The probability of winning the contest is therefore determined by (1) the level of investment in lobbying activities, $L_{A}$ and $L_{B}$; and (2) the effect of the relative size of NGO-A, $d$. The best way of thinking of $d$ is as the relative lobbying abilities of the NGO. This can represent many different attributes such as the size of the budget, number of employees, etc. The probability of winning the contest is also affected by (3) the economic status of the NGOs which is the inverse of their involvement with the poor, $v_{A}$ and $v_{B}$; and (4) the preferences of the donor with respect to poverty, $\alpha, 0 \leq \alpha \leq \infty$ (or the tolerance of the donor of poverty). As $\alpha$ increases the donor puts greater emphasis on the NGO's involvement with the poor. If $\alpha=$ 
0 , the donor does not have preferences over poverty, and, thus, the payoff depends only on the NGO's investment in lobbying activities. If $\alpha=\infty$, the donor puts all the weight on one NGO’s needs.

Each NGO maximizes its expected payoff. The optimal lobbying effort of both parties that satisfies the first order condition, $\frac{\partial E\left(U_{i}\right)}{\partial L_{i}}=0$ (it can be verified that the second order conditions hold, $\frac{\partial^{2} E\left(U_{i}\right)}{\partial L_{i}{ }^{2}}<0$ ) is given by

$$
L_{i}^{*}=\frac{d R v_{i}^{\alpha} v_{j}^{\alpha+1}}{\left(v_{A}^{\alpha+1}+d v_{B}^{\alpha+1}\right)^{2}} \quad \text { for } i, j=A, B \text { and } i \neq j
$$

Proposition 1: (a) If NGO-A's involvement with the poor is greater than that of NGO-B, the (relatively) larger is NGO-A (the better it is at lobbying or the more influential it is) the less lobbying effort will be invested by both NGOs. (b) If the involvement with the poor of NGO-A is less than those of $\mathrm{NGO}-\mathrm{B}$, then the effect the relative size of NGO-A has on the lobbying effort of both NGOs. This result states that if NGO-A is larger than NGO-B and A's involvement with the poor is greater, then both NGOs will decrease their lobbying efforts. NGO-A has a natural advantage both via the size of the NGO-A and in terms of its involvement with the poor.

Proof: from (3) it is clear that

$$
\begin{aligned}
& \frac{\partial L_{i}^{*}}{\partial d}=\frac{R v_{i}^{\alpha} v_{j}^{\alpha+1}\left(v_{A}^{\alpha+1}-d v_{B}^{\alpha+1}\right)}{\left(v_{A}^{\alpha+1}+d v_{B}^{\alpha+1}\right)^{2}} \forall i, j=A, B \text { and } i \neq j \text { thus } \operatorname{Sign}\left(\frac{\partial L_{B}^{*}}{\partial d}\right)=\operatorname{Sign}\left(\frac{\partial L^{*}{ }_{A}}{\partial d}\right)_{<}^{>} 0 \\
& \text { if } \frac{v_{A}}{v_{B}}<\sqrt[(\alpha+1)]{d} \text {. If } v_{A}<v_{B} \text { then } \operatorname{Sign}\left(\frac{\partial L^{*}{ }_{B}}{\partial d}\right)=\operatorname{Sign}\left(\frac{\partial L^{*}{ }_{A}}{\partial d}\right)<0 \text {, otherwise the sign of }
\end{aligned}
$$
the effect of a change in $d$ is ambiguous. 
Let us now consider how changes in the needs of the different NGOs affect their lobbying efforts. From the derivative of the lobbying effort with regard to the involvement with the poor of the NGOs we obtain,

Proposition 2: If the involvement with the poor of NGO-A is sufficiently small, but not too small, then: (1) a decrease in the involvement of NGO-A will increase NGO-A's lobbying effort and will decrease NGO-B's lobbying effort; (2) a decrease in NGO-B's involvement will increase the lobbying effort of NGO-A and will decrease NGO-B's lobbying effort.

Proof: From (3) it is clear that $\frac{\partial L_{i}^{*}}{\partial v_{i}}=s d R v_{i}^{\alpha-1} v_{j}^{\alpha+1}\left(-v_{i}^{\alpha+1}(2+\alpha)+\alpha d v_{j}^{\alpha+1}\right)$, $\frac{\partial L_{A}^{*}}{\partial v_{B}}=s(1+\alpha) R v_{A}^{\alpha} v_{B}^{\alpha}\left(v_{A}^{\alpha+1}-d v_{B}^{\alpha+1}\right)$, and $\frac{\partial L_{B}^{*}}{\partial v_{A}}=-\frac{\partial L_{A}^{*}}{\partial v_{B}}$ where $s=\frac{1}{\left(v_{A}^{\alpha+1}+d v_{B}^{\alpha+1}\right)^{3}}$. Thus $\sqrt[(\alpha+1)]{\frac{2}{\alpha d}+1}>\frac{v_{A}}{v_{B}}>\sqrt[(\alpha+1)]{d}, \quad$ then $\quad \operatorname{Sign}\left(\frac{\partial L_{A}^{*}}{\partial v_{A}}\right)=\operatorname{Sign}\left(\frac{\partial L_{A}^{*}}{\partial v_{B}}\right)<0, \quad$ and $\operatorname{Sign}\left(\frac{\partial L_{B}^{*}}{\partial v_{A}}\right)=\operatorname{Sign}\left(\frac{\partial L_{B}^{*}}{\partial v_{B}}\right)>0$

In other words, with the value of $d$ given, if the involvement with the poor of NGO-A is sufficiently small relative to those of NGO-B, then a decrease in A's involvement makes the two NGOs closer to each other in their involvement with the poor. The conditions above state what will happen to the total lobbying efforts of the NGOs as one has increased and the other has decreased its effort.

Let us now consider the effect of a change in preferences or the degree of tolerance towards poverty, $\alpha$, on the total lobbying effort for aid on the part of the NGOs. The total rent dissipation (the sum of lobbying effort) for both NGOs equals $R D=L_{A}^{*}+L_{B}^{*}=\frac{d R v_{A}^{\alpha} v_{B}^{\alpha}\left(v_{A}+v_{B}\right)}{\left(v_{A}^{\alpha+1}+d v_{B}^{\alpha+1}\right)^{2}}$. 
Proposition 3: If preferences with respect to the poverty (or tolerance) levelares not sufficiently high, then decreasing the tolerance to poverty will cause at least one of the NGOs to invest more effort in lobbying activities to offset donor preferences and to convince the donor that the tolerance of the donor is incorrect (this may of course lead the other NGO to also increase its effort). However, if the tolerance to poverty is sufficiently low, then the total lobbying effort will decrease as lobbying becomes less effective.

Proof: Since $R D=L_{A}^{*}+L_{B}^{*}=\frac{d R v_{A}^{\alpha} v_{B}^{\alpha}\left(v_{A}+v_{B}\right)}{\left(v_{A}^{\alpha+1}+d v_{B}^{\alpha+1}\right)^{2}}$ and without loss of generality assume that $v_{A}>v_{B}$ we obtain that $\frac{\partial R D}{\partial \alpha}=s d R v_{A}^{\alpha} v_{B}^{\alpha}\left(v_{A}+v_{B}\right)\left(-v_{A}^{\alpha+1}+d v_{B}^{\alpha+1}\right)\left(\operatorname{Ln}\left(v_{A}\right)-\operatorname{Ln}\left(v_{B}\right)\right)$.

Therefore, $\frac{\partial R D}{\partial \alpha}<0$ iff $\frac{\operatorname{Ln}(d)}{\operatorname{Ln}\left(v_{A}\right)-\operatorname{Ln}\left(v_{B}\right)}<\alpha+1$.

The reason for this result is that by decreasing tolerance of poverty the donor requires more activity by one NGO to convince the donor that it really needs the funds. This, of course, may cause the other NGO to also increase its lobbying effort.

A.2. Competition for the NGOs Patronage. We now examine competition between the subgroups the NGO seeks to serve. NGO-A spends $L_{A} v_{A}$ in order to gain a proportion of $\operatorname{Pr}_{A}^{*}$ out of the total aid R. Thus, the net aid that NGO-A has to divide between its subgroups is given by: $\operatorname{Pr}_{A} R-L_{A} v_{A}$. To simplify we assume that there are only two subgroups in each NGO $(i=1,2)$ competing for the funds. There is no conflict between the assumptions of having two subgroups in each NGO and that the size of the NGOs may differ. The expected payoffs for the subgroups are given by:

$$
E\left(u_{i}\right)=w_{i}\left(1-l_{i}\right)+g_{i}\left(\operatorname{Pr}_{A} R-L_{A} v_{a}\right),
$$


where $w_{i}$ is the economic status (its lack of poverty) of subgroup $i, l_{i}$ is the lobbying effort of the subgroup and $g_{i}$ is the probability/proportion that subgroup $i$ will receive/win a payment. Denote by $z$ the weight assigned by the NGO to the needs of subgroup $I$, representing the relative size of this subgroup, the NGO's preferences or the lobbying capability of the subgroup. It is assumed that as $l_{i}$ increases so does $g_{i}$ and as $l_{j}$ increases, $g_{i}$ decreases, as $\mathrm{z}$ increases $g_{i}$ increases and $g_{j}$ decreases. Moreover, as $w_{i}$ increases $g_{i}$ decreases and $g_{j}$ decreases. The NGO's preference/tolerance of poverty of the subgroups are given by $\beta$. We assume that as the NGO is more sensitive to poverty, an increase in $\beta$, the probability that the poorer subgroup will receive a larger part of the aid increases.

Each subgroup maximizes its expected payoff $\frac{E\left(u_{i}\right)}{\partial l_{i}}=0 .^{5}$ The net aid facing NGOA is negatively related to the economic status of NGO-A (an increase in $v_{A}$, a decrease in the involvement with the poor of NGO-A), positively related to the economic status of NGO-B, and positively related to the size of NGO-A $(d)$ : We therefore obtain,

$$
\operatorname{Pr}_{A}^{*} R-L_{A}^{*} v_{A}=2 \frac{d R v_{1}^{1+\alpha} v_{2}{ }^{2+2 \alpha}}{\left(v_{1}^{1+\alpha}+v_{2}{ }^{1+\alpha}\right)^{3}}
$$

It can easily be verified that

Proposition 4: As NGO-A is larger relative to NGO-B (its lobbying abilities are better than those of NGO-B or the donor prefers NGO-A to NGO-B) the net aid that NGO-A receives increases and the lobbying effort by the subgroups in NGO-A also increases.

Case B. Direct versus indirect donation: which dominates? 
We now compare the lobbying efforts and the probability that subgroups with higher poverty will receive more funds in two different situations: a two and one stage contest. The idea here is to contrast the donor providing aid via the NGOs to the subgroups with the donor providing aid directly to the subgroups. Assume that the contest success function in the contest between the subgroups within the NGO is given by (in a similar way to the contest success function presented above):

$$
g_{i}=\left\{\begin{array}{l}
\frac{z_{A} l_{i} w_{i}^{-\beta_{A}}}{z_{A} l_{i} w_{i}^{-\beta_{A}}+l_{j} w_{j}^{-\beta_{A}}} \text { for } i \neq j, i, j=1,2 \\
\frac{z_{B} l_{i} w_{i}^{-\beta_{B}}}{z_{B} l_{i} w_{i}^{-\beta_{B}}+l_{j} w_{j}^{-\beta_{B}}} \text { for } i \neq j, i, j=3,4
\end{array}\right. \text {. }
$$

Calculating the total expenditure of both subgroups in each NGO we obtain in a similar way to what we obtained above,

$$
l_{1}^{*}+l_{2}^{*}=\frac{z_{A} r_{A}^{*} w_{1}^{\beta_{A}} w_{2}^{\beta_{A}}\left(w_{1}+w_{2}\right)}{\left(w_{1}^{\beta_{A}+1}+z_{A} w_{2}^{\beta_{A}+1}\right)^{2}} \text { and } l_{3}^{*}+l_{4}^{*}=\frac{z_{B} r_{B}^{*} w_{3}^{\beta_{B}} w_{4}^{\beta_{B}}\left(w_{3}+w_{4}\right)}{\left(w_{3}^{\beta_{B}+1}+z_{B} w_{4}^{\beta_{B}+1}\right)^{2}} \text {. }
$$

In order to help understand these results let us consider the following specific cases: (1) both NGOs have the same size and have the same lobbying abilities: $d=1$; (2) NGOs do not have particular preferences regarding the division of the aid between the subgroups and all subgroups have the same lobbying capabilities $z_{A}=z_{B}=1$; (3) subgroups 2 , 3 and 4 have the same "lack of poverty" or endowment denoted by $w\left(w_{2}=w_{3}=w_{4}=w\right)$ and subgroup number 1's poverty is twice as much as the others: $w_{1}=0.5 w$; (4) the weighted economic status of an NGO is the sum of the endowment's' of the subgroups: $v_{A}=w_{1}+w_{2}$ and $v_{B}=w_{3}$ $+w_{4}$; and (6) the preference/tolerance of poverty of the NGOs and the donor are the same and equal to 1: $\alpha=\beta_{A}=\beta_{B}=1$. 
In this situation we can calculate the total investment in lobbying effort in both stages by all four subgroups and both NGOs and the expected payoff to the worst-off subgroup (number 1).

B.1. Indirect donation. The total expenditure of and the payoff to subgroup 1 in the two stage contest equals:

$$
\operatorname{Total}_{\text {two }}=\sum_{j=A, B} L_{j}^{*}+\sum_{i=1}^{4} l_{i}^{*}=0.3811 \frac{R}{w}
$$

and,

$$
E\left(u^{*}\right)_{t w o}=0.5 w+0.1888524 R \text {. }
$$

B.2. Direct donation. Now let us consider the case where all four subgroups lobby directly the donor in a one-stage game. We assume that the contest success function is given by:

$$
f_{j}=\frac{x_{j} w_{j}^{-\beta}}{\sum_{i=1}^{4} x_{i} w_{i}^{-\beta}} \quad \forall j=1, . ., 4 .
$$

This function satisfies the general properties presented above. Each subgroup maximizes its expected payoff $\frac{E\left(u_{i}\right)}{\partial l_{i}}=0 \quad \forall i=1,2,3,4$. Solving all four first order conditions together while assuming both NGOs serve the same sized populations and have the same lobbying abilities, subgroups 2, 3 and 4 have their same endowments denoted by $w\left(w_{2}=w_{3}=w_{4}=w\right)$ and subgroup number 1 's poverty is twice as much as the others: $w_{1}=0.5 \mathrm{w}$ and $\beta=1$, we obtain:

$$
l_{1}^{*}=0.35503 \frac{R}{w}, \quad l_{2}^{*}=l_{3}^{*}=l_{4}^{*}=0.0710059 \frac{R}{w} .
$$

The total lobbying effort in the one-stage game equals 


$$
\text { Total }_{\text {one }}=\sum_{i=1}^{4} l_{i}^{*}=0.568047 \frac{R}{w} \text { and } E\left(u^{*}\right)_{\text {опе }}=0.5 w+0.591716 R \text {. }
$$

Thus,

Proposition 5: Given the above values of the parameters, total expenditure of the subgroups is higher in the one-stage contest than in the two-stage contest. The expected payoff to the worst-off subgroup increases in a one-stage contest relative to what it would have achieved in a two-stage contest. If the donor's objective is to help the worst-off subgroup as much as possible, it prefers a one-stage contest. However, if the donor prefers to minimize wasted resources on lobbying, then a two-stage contest is optimal.

In the direct one-stage contest, the better off subgroup may not receive any aid. However, when the NGO makes its presentation to the donor it is selling the donor on what it can do to help the donor achieve its goals, so the NGO is representing all its "clients,” both the worse off and the best off groups. The subgroups then appeal to the NGO for aid (net of the costs of the NGO). This increases the chances the better off subgroup will obtain aid funds.

B.3. Information and the NGOs. Another important aspect that should be considered when comparing a one-stage to a two-stage contest is the preference/tolerance towards the poverty of the donor verses that of the NGO regarding the economic status of the subgroups. It is reasonable to assume that the NGO has more information regarding the different groups and thus has a lower level of tolerance than that of the donor. Decreasing tolerance increases the probability that the correct subgroup receives the resources. However, decreasing tolerance, as we saw in Proposition 3, may increase the total wasted resources invested in lobbying activities. A two-stage contest has the advantage that after the NGO receives the resources it allocates the resources correctly with a higher probability than in a one-stage contest. However, the resources that the NGO receives may be low as the donor lacks information regarding the actual situation of the NGO. 
B.4. Are NGOs always the good guys? Consider the relationship between the NGO's payoff and the poverty of the subgroups. From (1), the expected payoff of NGO $i$ in equilibrium is given by

$$
E\left(U_{i}^{*}\right)=\left(1-L_{i}^{*}\right) v_{i}+\operatorname{Pr}_{i}^{*} R
$$

For NGO-A, where we normalize $v_{B}$ to unity and $\alpha=1$ :

$$
E\left(U_{A}^{*}\right)=\left(1-L_{A}^{*}\right) v_{A}+\operatorname{Pr}_{A}^{*} R=\frac{v_{A}^{5}+2 v_{A}^{3} d+\left(v_{A}+R\right) d^{2}}{\left(v_{A}^{2}+d\right)^{2}}
$$

The effect a change in, $v_{i}$, the economic status of the NGO, has on the equilibrium expected payoff is

$$
\frac{\partial E\left(U^{*}{ }_{A}\right)}{\partial v_{A}}=\frac{v_{A}{ }^{6}+3 v_{A}{ }^{4} d+3 v_{A}{ }^{2} d^{2}+d^{3}-4 v_{A} d^{2} R}{\left(v_{A}{ }^{2}+d\right)^{2}} .
$$

Equation (14) tells about the relationship between the economic status of an NGO and its expected equilibrium payoff from the donor, which is the aid it receives to dispense. The economic status of an NGO in its 'endowment', how much it has on its own to give away. The relationship is not linear. If the NGO is very poorly endowed then as it increases its endowment its expected payoff (aid to dispense) will increase. If instead the NGO is moderately endowed then the NGO gains from reducing its endowment level, as the decrease in endowment would be lower than the increase in aid received from the donor. On the other hand, if this is a "rich" NGO, if the NGO's endowment is sufficiently high, its gains from the lobbying activities are low and the NGO prefers to build up its endowment. ${ }^{6}$

The idea behind this result is that if the NGO does not have a large endowment, it is beneficial for it to shed some of its endowment and become worse-off which in turn increases the probability of receiving funds from the donor (see Konrad, 1994, for a similar result in the case of the provision of public goods). The question is therefore: how can an NGO receive 
funds from the donor and become worse-off or at least sustain its low-income position? Becoming worse-off is easier than becoming economically better off. Remember that the donor and the NGOs do not have the same level of tolerance/preferences of poverty. The NGOs are assumed to have less tolerance to poverty than the donor. Thus the NGO can allocate the funds to the subgroups that are not the worse-off ones, sustaining the low levels of the worse-off subgroups. For example, funds that should go to education and health could go elsewhere. The NGO thus may be able to sustain low education and income levels of the average population. The lobbying system has therefore developed a poverty trap under which once you are in the trap the NGO would not wish to exit it. We may summarize this result in the following way

Proposition 6: If the endowment of NGO-A is not sufficiently low nor sufficiently high, the NGO prefers to allocate the funds it receives from the donor in a way that sustains the low endowment of its population rather than allocating the funds in a way that increases its population's endowment.

\section{Conclusion}

Different groups lobby the donor in order to receive the donor's support. One such group is nongovernmental organizations (NGOs), which are increasingly playing a role between the donor and the final recipient. NGOs, and well as organizations representing the subgroup potential recipients, attempt to capture part of the aid that the donor has to give out. Thus, it is not clear that aid will be allocated properly, say to the poorest or to maximize the social welfare. Rather, aid may be allocated to the efficient aid-seekers.

If aid is allocated to the efficient aid-seekers or those that invest a lot of effort and resources in aid-seeking activities, there are two efficiency losses: (a) the poorest may not 
receive the funds and (b) the investment of effort and resources in aid-seeking activities decreases the resources allocated to real production and thus decreases output. In an attempt to increase efficiency the donor may decentralize decision-making by allocating aid to different NGOs. The NGOs, in turn, will allocate aid to the different groups within its domain.

We analyze this decentralization of decision-making in a theoretical rent-seeking framework. We take into account the preferences and tolerance the donor has regarding the needs of the different groups and the tolerance of the NGO to poverty has regarding these groups. We also provide some insight into the question of how decentralization increases or decreases total aid-seeking activity, and how the level of tolerance to poverty possessed by the donor and the NGOs affects aid-seeking activity and the probability of receiving transfers.

A consequence of tolerance to poverty and hierarchical contests may be the development of a poverty trap. In order to continue to receive transfers based on poverty an NGO may deliberately allocate funds away from the poorest so as not to better their position. In a lobbying contest incentives may work in non-obvious ways. 


\section{References:}

Allard, Richard J., “Rent-Seeking with Non-Identical Players,” Public Choice, 57(1988):314.

Anheier, Helmut K., Marlies Glasius and Mary Kaldor (eds.), Global Civil Society. Oxford: Oxford University Press, 2001.

Baik, Kyung-Hwan and Sanghack Lee, "Two-Stage Rent-Seeking Contests with Carryovers,” Public Choice, 103(2000):285-96.

Chau, Nancy H. and Marieke Huysentruyt, "Nonprofits and Public Good Provision: A Contest based on Compromises,” manuscript (2005).

Epstein, Gil S. and Ira N. Gang, "Governments and Cities: Contests and the Decentralization of Decision Making," IZA Working Paper 547 (2003).

Epstein, Gil S. and Shmuel Nitzan, "Endogenous Public Policy, Politicization and Welfare,” Journal of Public Economic Theory 4 (2002a):661-77.

Epstein, Gil. S. and Shmule Nitzan, "The Politics of Randomness," CES-IF0 Working Paper Series No. 803 (2002b).

Epstein, Gil S. and Shmuel Nitzan, "Political Culture and Monopoly Price Determination,” Social Choice and Welfare, 21 (2004):1-19.

Gradstein, Mark, “Efficient Provision of a Discrete Public Good,” International Economic Revie. 35 (2004):877-97.

Grossman, Gene M. and Elhanan Helpman, "Protection for Sale," American Economic Review, 84(1994):833-50.

Konrad, Kai A., “The Strategic Advantage of Being Poor: Private and Public Provision of Public Goods,” Economica 61(1994):79-92. 
Nitzan, Shmuel, “Modelling Rent-Seeking Contests,” European Journal of Political Economy, 10(1994):41-60.

Nti, Kofi O., “Rent-Seeking with Asymmetric Valuations,” Public Choice 98(1993-4):41530.

OECD (Organisation for Economic Co-operation and Development), Statistical Annex of the 2003 Development Co-operation Report (www.oecd.org/dac/stats/dac/dcrannex, accessed December 6, 2004).

Smith, Stephen C., "Governance of Nongovernmental Organizations: A Framework and Application to Poverty Programs in East Africa" (August 25, 2004). GWU Law School Public Law Research Paper No. 117. http://ssrn.com/abstract=628684 .

Tullock, Gordon, “Efficient Rent-seeking,” in James M. Buchanan, Robert.D. Tollison, and Gordon Tullock, (eds.), Toward a Theory of the Rent-seeking Society (College Station, Texas: A\&T Press, 1980). 


\section{Endnotes :}

${ }^{1}$ See Anheier, Glasius and Kaldor (2001, Table R23b, page 300) for the number of NGOs and the OECD (2004, Tables 13e and 14e) for the other statistics in the paragraph.

${ }^{2}$ Chau and Huysentruyt (2005) in analyzing NGO structure and Smith (2004) in examining NGO governance provide excellent and concise summaries of contributions in economics to understanding the role of NGOs in international aid.

${ }^{3}$ For example, an alternative scenario might have many NGOs competing to support the same subgroup. Or, the NGO may not be allowed to talk to locals, but must act through the government as an intermediary or even final recipient. In this case the NGO has to figure out where in the government to target the assistance. Also, we abstract from attempts at aid harmonization and coordination among donors, NGOs and recipient governments.

${ }^{4}$ The donor may create a contest in order to extract from the NGOs and subgroups specific commitments.

${ }^{5}$ Second order conditions are satisfied.

6 These results can readily seen in the second order condition and its sign, $\frac{\partial^{2} E\left(U_{A}^{*}\right)}{\partial v_{A}{ }^{2}}=\frac{4\left(5 v_{A}{ }^{2}-d\right) d^{2} R}{\left(v_{A}{ }^{2}+d\right)^{4}}$ If $5 v_{A}{ }^{2}>d$ then the expected payoff is $U$ shaped and if $5 v_{A}^{2}<d$ the expected payoff has an inverse $U$ shape. 